\title{
PREPARATION AND CHARACTERIZATION OF POROUS HYDROXYAPATITE AND ALGINATE COMPOSITE SCAFFOLDS FOR BONE TISSUE ENGINEERING
}

\author{
DECKY J INDRANI ${ }^{1 *}$, EMIL BUDIYANTO² ${ }^{2}$ HAYUN HAYUN ${ }^{3}$ \\ ${ }^{1}$ Department of Dental Materials Science, Faculty of Dentistry, Universitas Indonesia, Jakarta, Indonesia. ${ }^{2}$ Department of Chemistry, \\ Faculty of Mathematics and Natural Sciences, Universitas Indonesia, Jakarta, Indonesia. ${ }^{3}$ Department of Pharmacy-Medicinal Chemistry \\ and Bioanalysis, Faculty of Pharmacy, Universitas Indonesia, Jakarta, Indonesia. Email: deckyji@gmail.com
}

Received: 16 September 2017, Revised and Accepted: 3 October 2017

ABSTRACT

Objective: To prepare and characterize composite scaffolds of a hydroxyapatite (HA) and an alginate having high viscosity.

Materials and Methods: HA powder was synthesized using wet chemical precipitation, the alginate powder was extracted from the Sargassum duplicatum seaweed, and the HA/alginate composite scaffolds were prepared by freeze-drying. X-ray diffraction and Fourier transform infrared techniques were utilized to characterize the HA and alginate, and electron microscopy was used to evaluate the HA and the HA/alginate composite scaffolds. The HA/alginate composite scaffold obtained from the commercially available HA and alginate powders were employed as a comparison.

Results: Synthesized HAs were identified as the HA phase, which contained absorbed water, phosphate, and carbonate groups. The extracted alginate contained the carboxyl, cyclic ether and hydroxyl groups. The scaffolds prepared from the HA and alginate mixture were three-dimensional and containing interconnected pores with a diameter ranging from 150 to $300 \mu \mathrm{m}$ and pore walls of a composite construction.

Conclusion: A three-dimensional scaffold was produced using a freeze-drying method from a composite of HA and the high viscosity alginate solution. The scaffold was highly porous and showed interconnected pores, with a diameter ranging from 150 to $300 \mu \mathrm{m}$.

Keywords: Alginate, Hydroxyapatite, Microstructure, Scaffold.

(c) 2017 The Authors. Published by Innovare Academic Sciences Pvt Ltd. This is an open access article under the CC BY license (http://creativecommons. org/licenses/by/4. 0/) DOI: http://dx.doi.org/10.22159/ijap.2017.v9s2.24

\section{INTRODUCTION}

In the past two decades, tissue engineering by bone regeneration has become an alternative method used to overcome the shortcomings of conventional bone defect treatments [1-4]. In tissue engineering, the application of biomaterials is increasing, and the development of porous media, the so-called scaffold, is an advanced multidisciplinary research effort meant to meet the tissue engineering demand for regenerating tissues $[5,6]$. Tissue engineering involves cells that are taken from a human body, and then seeding them onto a scaffold and implanting them into the body where they grow and eventually become new bone tissue. In artificial tissue construction and regeneration, growing cells with an engineered scaffold should enhance the development of artificial tissues [7-9]. Therefore, the scaffolds should mimic the bone structure and provide space (pores) for the seeded cells.

Bone is a composite structure of organic materials, mainly a collagen matrix, and inorganic phases, mainly bone apatite, which mineralizes the matrix. The exterior consists of cortical bone, which is solid with only a few small canals. The interior contains trabecular bone, which resembles scaffolding or a honeycomb. The spaces between bones are filled with fluid bone marrow cells, which make blood, and some fat cells [10].

Calcium phosphate ceramics, particularly macroporous hydroxyapatite (HA), are ideal for bone tissue engineering because they are similar to apatite bone. Moreover, they are able to produce scaffolds with interconnected pores $[6,11]$. However, the conflicting requirements for porosity and strength have limited its use as a scaffold. In the past several decades, addition of biopolymers to bioceramics and to produce composite scaffolds is known to form pores and enhance mechanical strength [12].
A vast number of scaffolds are obtained from mixtures of ceramic and biopolymer materials. Composites of HA and collagen have been studied to produce composite scaffolds $[13,14]$. Gelatin, the cost-effective, denatured form of collagen, has also been combined with HA [15]. Due to its remarkable antibacterial activity, chitosan, a natural cationic, has been used to prepare HA/chitosan composited scaffolds [16]. Alginate, a natural resource of polysaccharides derived from seaweed, is widely used in biomedical purposes $[17,18]$. Recently, alginate-based scaffolds, such as $\mathrm{HA} /$ alginate and $\mathrm{HA} /$ alginate/chitosan composites, have been developed for bone tissue engineering $[19,20]$. Particularly, HA/ alginate composite scaffolds have been found to increase the pore size of bone $[21,22]$. Because large pores may be suitable for cell attachment in the inner parts of a scaffold, the HA/alginate scaffold may offer an alternative for bone tissue engineering.

Alginate $\left[\left(\mathrm{C}_{6} \mathrm{H}_{7} \mathrm{O}_{6} \mathrm{Na}\right)_{n}\right]$, a natural resource of polysaccharides derived from brown seaweed, composed of 1-4- $\beta$-D mannuronic and L-guluronic acids contains a large number of pendant carboxylic acid groups, which provide sites for heterogeneous mineral nucleation [23-25]. Alginate is highly hydrophilic that can form stable hydrogels in the presence of certain divalent cations, such as $\mathrm{Ca} 2+, \mathrm{Mg} 2+, \mathrm{Fe} 2+, \mathrm{Ba} 2+$, or $\mathrm{Sr} 2+. \mathrm{Ca} 2+$ is one of the most commonly used divalent cations to ionically crosslink with alginate [26,27].

In the search for new resources to potentially produce alginates, one abundant type of brown seaweed (algae), Sargassum duplicatum from the coast of Banten of Indonesia, has been identified and have become an attractive material for food [28-30]. However, alginates have not been studied for biomedical applications. Extracted alginate $S$. duplicatum solution has been found to be more viscous, with relatively high viscosity compared to that of the commercially available alginate [31]. To more accurately mirror the structure of bone, a composite of HA 
and alginate, both substituting for bone apatite and collagen, has been considered. Traditional methods for producing porous biopolymerbased scaffolds include gas foaming, solvent casting, phase separation, particulate leaching, and freeze-drying. Compared to the other methods, freeze-drying is the easiest way to fabricate porous scaffolds. Since freeze-drying can be used for bioceramic and biopolymer materials, freeze-dried structures can produce a wide pore when both materials are used to construct a scaffold [22]. Moreover, with water as the solvent, the process is environmentally-friendly. Therefore, the objective of this study, therefore, was to prepare and characterize an experimental composite scaffold of a HA and an alginate having high viscosity.

\section{MATERIALS AND METHODS}

\section{Materials}

Reagents, i.e. ,H3PO4, $\mathrm{Ca}(\mathrm{OH})_{2}, \mathrm{HCl}$, and $\mathrm{Na}_{2} \mathrm{CO}_{3}$ and the commercially available HA (used for tissue engineering) and alginate were obtained from Sigma-Aldrich (Merck, USA. The synthesized HA and extracted alginate were obtained by preparation

\section{Synthesis of HA powder}

The wet chemical method was conducted following the technique for the synthesis of HA nanoparticles that was indicated by Bouyer et al. $[32,33]$. Briefly, the $\mathrm{H}_{3} \mathrm{PO}_{4}$ solution was added to the $\mathrm{Ca}(\mathrm{OH})_{2}$ solution using titration. The solutions were vigorously stirred and then aged until white precipitates formed. The precipitates were collected, filtered and washed, dried in a vacuum oven and calcined at $750^{\circ} \mathrm{C}$. The synthesized HA powder was ground, and then stored in a desiccator.

\section{Extraction of alginate powder}

The brown seaweed species, $S$. duplicatum, was collected from the reef flats of the Pamengpeuk shore of Banten, in West Java of Indonesia. Once harvested, the seaweed specimens were washed with water to remove dirt, air dried and stored in the shade at a ventilated site. Extraction of alginate was carried out using the method reported in previous studies [24,31].

In short, the dried seaweed specimens were soaked in water overnight at room temperature, and then washed with distilled water and stored in $0.3 \% \mathrm{HCl}$ solution for $1 \mathrm{~h}$, after which they were washed again with distilled water. They were then immersed in $2 \% \mathrm{Na}_{2} \mathrm{CO}_{3}$ solution for $1 \mathrm{~h}$, and water was added before it was left to stand overnight.

The viscous mixture was separated from its residue under continuous stirring and controlled heating at $100^{\circ} \mathrm{C}$ for $3 \mathrm{~h}$. After this, the supernatant was separated, and the soluble fraction of alginate filtrate was filtered using a vibration screen, and then acidified using a $10 \%$ $\mathrm{NaCl}$ solution until a $\mathrm{pH}$ of 3 was obtained. Next, the filtrate was gently stirred until thick foam floated at the surface.

The filtrate was then filtered and rinsed with water and $\mathrm{NaOH}$ solution to reduce its acidity until a $\mathrm{pH}$ of 7 was obtained. The obtained fiber was milled with a blender, and then dried followed by grinding to produce the alginate powder.

\section{Preparation of the HA/alginate composite scaffolds}

The synthesized HA and the extracted alginate powders were used to prepare the HA/alginate composite scaffolds, based on the freezedrying method adopted from an existing technique [22]. First, the alginate $(3 \% \mathrm{w} / \mathrm{v})$ solution was prepared by dissolving alginate powder in distilled water under stirring (Heidolph MR 3001, Germany) at $900 \mathrm{rpm}$ for $2 \mathrm{~h}$, and then HA powder was added to the alginate solution under stirring at room temperature for $2 \mathrm{~h}$. Next, a crosslinker $0.03 \mathrm{M}$ $\mathrm{CaCl}_{2}$ aqueous solution was added drop by drop into the HA/alginate solution under gentle stirring. After titration, the mixture was stirred completely with a mechanical stirrer at $900 \mathrm{rpm}$ for $6 \mathrm{~h}$ to obtain a perfect HA/alginate gel. It was then left to stand overnight to remove the air bubbles. All processes were carried at room temperature.
For preparing the scaffolds, HA/alginate gel was then subjected to the freeze-drying process. The HA/alginate composite gel was molded in glass molds $(\varnothing=16 \mathrm{~mm}$, thickness $=5 \mathrm{~mm})$ and initially frozen at $-40^{\circ} \mathrm{C}$ (Biotron CleanVac, Korea) for 24 h. Subsequently, the gel continued to undergo freeze-drying at 0.1-0.2 torr at the same temperature for another $24 \mathrm{~h}$. This process produced the experimental HA/alginate composite scaffolds. HA/alginate composite scaffolds prepared from the commercially available $\mathrm{HA}$ and alginate were employed for a comparison.

\section{The X-ray diffraction (XRD) measurement}

XRD, as described by Rietveld refinement method, was used to identify the HA phase. Each of the molded powders was scanned using a diffractometer (Phillip PW-2213/20, The Netherlands) with CuK $\alpha$ radiation. The samples were scanned using a step-scanning method in a diffraction angle ranging from $5^{\circ}$ to $55^{\circ}$.

\section{Fourier transform infra-red spectroscopy analysis}

Fourier transform infrared (FTIR) spectroscopy was used to analyze the chemical state of the HA and alginate powders. Approximately $2 \mathrm{mg}$ of each sample was prepared using the $\mathrm{KBr}$ pellet technique and molded into a plastic ring mold $(0.5 \mathrm{~mm}$ in thickness and $2.5 \mathrm{~cm}$ in diameter), and then hydraulically pressed into a pellet. The samples were then mounted into the FTIR apparatus (Spectrum One, Perkin Elmer, Japan) at $4 \mathrm{~mm} / \mathrm{s}$ with transmittance spectra ranging from 450 to $3500 \mathrm{~cm}^{-1}$.

\section{Electron microscopic determination}

The microstructure of the HA powders and the HA/alginate scaffolds were observed using scanning electron microscopy (SEM) (JEOL, JSX3211, Tokyo, Japan). For the experimental HA/alginate scaffolds, the samples were cut in cross-sections. Before the test, each sample was mounted onto aluminum stubs and gold-coated.

\section{RESULTS AND DISCUSSION}

\section{Phase identification}

The XRD profiles of HA powders are given in Fig. 1

The XRD profiles of the HA powders are shown in Fig. 1. Fig. 1a shows the characteristic peaks at major planes (002), (210), (211), (112), (300), (202), and (310), which were in good agreement with those in the ICDD Card No. 09-0232, thus identifying that the synthesized HA was in the HA phase. The XRD Rietveld refinement of the peaks showed that there was no phase other than the HA phase. The XRD profiles of the synthesized HA (Fig. 1a) demonstrate broad peaks, showing that the crystallinity of the synthesized HA was lower than that of the commercially available HA, which has sharp peaks. This was likely to be due to impurity in the synthesized HA (Fig. 2a). However, for tissue engineering purposes, the profiles of the synthesized HA were in agreement with the profiles of the commercially available HA (Fig. 1b).

\section{Functional groups}

The FTIR spectra presented in Fig. 2 are from the HA powder.

As seen in the FTIR spectrum results for the synthesized HA (Fig. 2a), an envelope around $3000-3500 \mathrm{~cm}^{-1}$ along with a peak at $1639 \mathrm{~cm}^{-1}$ are assigned to the hydroxyl $(\mathrm{O}-\mathrm{H})$ group, which indicates that adsorbed water has accumulated in the structure. The main signal, which appeared in triplicate at around $1000-1100 \mathrm{~cm}^{-1}$, was for the phosphate (P-O) groups; signals at $962,642,564$, and $475 \mathrm{~cm}^{-1}$ are also represented. The band clearly seen at $631 \mathrm{~cm}^{-1}$ is attributed to the $\mathrm{O}-\mathrm{H}$ from the absorbed water, thereby confirming the formation of HA. The peaks at $1449 \mathrm{~cm}^{-1}$ and $1412 \mathrm{~cm}^{-1}$ indicate the carbonate $\left(-\mathrm{CO}_{3}\right)$ groups, which is an impurity incorporated into the HA structure. This condition is biomimetic to human bone, which is carbonated. The occurrence of the $\left(\mathrm{CO}_{3}\right)$ groups may be explained by the broad peaks shown in the XRD profiles (Fig. 1a).

With respect to the commercially available HA (Fig. 2b), the peak for the absorbed $\mathrm{O}-\mathrm{H}$ group was clearly seen at $634 \mathrm{~cm}^{-1}$; however, the 


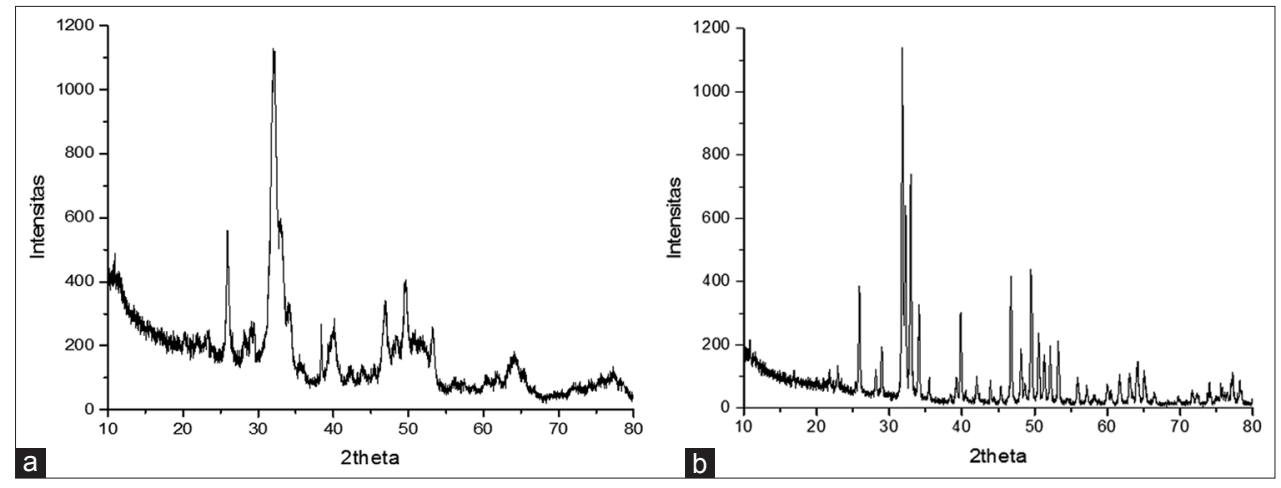

Fig. 1: X-ray diffraction profiles of the (a) synthesized and (b) commercially available hydroxyapatite

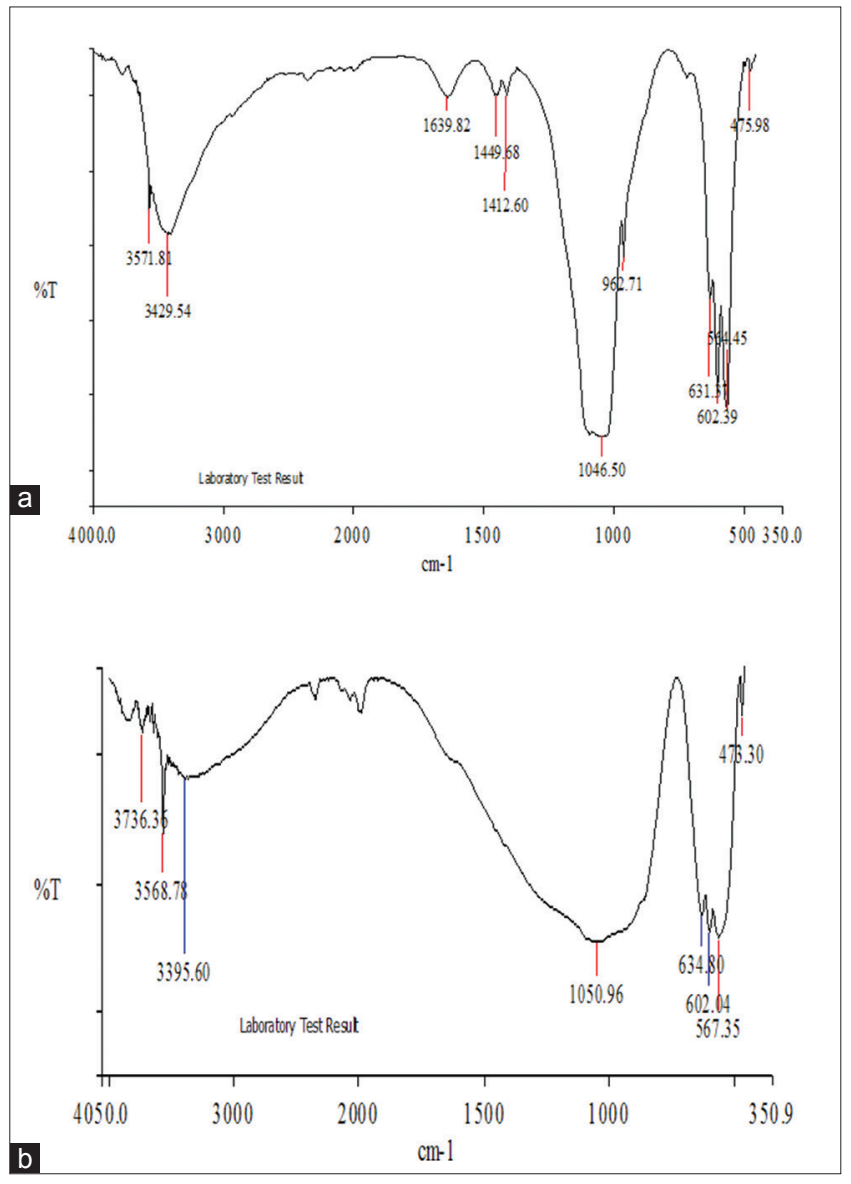

Fig. 2: Fourier transform infrared spectra of the (a) synthesized and (b) the commercially available hydroxyapatite

peak for $-\mathrm{CO}_{3}$ was unclear due to the broad peak attributed to the $\mathrm{P}-\mathrm{O}$ group. The peak in the $2300-800 \mathrm{~cm}^{-1}$ region is attributed to the main signal in triplicate of the P-Ogroup, which appears to be broader than normal. This condition probably occurred because more phosphate was included in the synthesis of the commercially available HA.

The FTIR spectra of the alginate powders are presented in Fig. 3. As seen in Fig. 3a, it is obvious that the extracted alginate showed broad peaks attributed to the hydroxyl $(0-\mathrm{H})$ groups at $3650 \mathrm{~cm}^{-1}, 3434 \mathrm{~cm}^{-1}$, and $555 \mathrm{~cm}^{-1}$. The peaks presented at $2910 \mathrm{~cm}^{-1}$ are assigned to the alkene $\left(\mathrm{C}-\mathrm{H}_{2}\right)$ groups. Characteristic peaks at $1623 \mathrm{~cm}^{-1}$ and $1414 \mathrm{~cm}^{-1}$ are due to the carboxyl $(\mathrm{C}=0)$ group.

Another characteristic peak at $1028 \mathrm{~cm}^{-1}$ represents the cyclic ethers $(\mathrm{C}-\mathrm{O}-\mathrm{C})$. The FTIR spectra of the extracted alginate are in agreement with the commercially available alginate (Figure $3 \mathrm{~b}$ ), which presented two peaks at $3401 \mathrm{~cm}^{-1}$ and $559 \mathrm{~cm}^{-1}$. The peaks at $2928 \mathrm{~cm}^{-1}$, $1626 \mathrm{~cm}^{-1}$, and $1419 \mathrm{~cm}^{-1}$, and another peak at $1027 \mathrm{~cm}^{-1}$ are attributed to the $\mathrm{O}-\mathrm{H}, \mathrm{C}-\mathrm{H}_{2}, \mathrm{C}=\mathrm{O}$, and $\mathrm{C}-\mathrm{O}-\mathrm{C}$ groups, respectively.

Microstructure of the HA and HA/alginate composite scaffolds Mixture of the alginate and HA has produced three-dimensional HA/ alginate scaffolds. The geometry of the scaffolds was $16 \pm 1 \mathrm{~mm}$ in diameter and $5 \pm 1 \mathrm{~mm}$ in thickness. The micrograph obtained from the SEM of the scaffolds was seen in Fig. 4.

Fig. $4 \mathrm{a} 1$ and $4 \mathrm{~b} 1$ presented the microstructure scaffolds of the experimental and commercially available HA/alginate scaffolds, respectively. Both scaffolds contained pores connected by pore walls. The average pore diameter was around 150-300 $\mu \mathrm{m}$. This diameter was in a range that is a key prerequisite for cell attachment and growth in the pore, which is $200-400 \mu \mathrm{m}$ [5]. The highly porous structure of the scaffolds was obtained by the freeze-drying method. When the HA/alginate gel was frozen, the water molecules produced ice crystals, which were then removed by freeze-drying through a sublimation process; hence, porous HA/alginate scaffolds were constructed.

The pore walls were seen as granules entrapped in a matrix throughout the scaffolds (Fig. $4 \mathrm{~b} 1$ and 4b2). The granules were HA grains distributed in the alginate that constructed a HA/alginate composite structure. The pore walls of the synthesized HA/alginate (Fig. 4b1) displayed a rough surface; however, the commercially available HA/alginate (Fig. 4b2) had a smooth surface. This condition may be related to the method of synthesizing HA carried out in this study.

In this study, the powder was obtained by the wet chemical precipitation, whereas, the commercially available HA was assumed to be synthesized by the self-assembly method using a template, as reported in Shi et al. [34]. The use of a silica mesoporous template has helped in locating $\mathrm{Ca}^{2+}$ and $\mathrm{PO}_{4}{ }^{3-}$ based on the template shape. After an aging period, removal of the template may leave an abundant amount of nanocrystalline HA according to the template. Therefore, it is possible that the HA particles were distributed more regularly throughout the alginate gel. However, in general, both the experimental and the commercially available HA/alginate scaffold displayed a bone-like microstructure similar to that of commercially available HA/alginate scaffolds.

The experimental HA/alginate scaffolds produced from the present study may be used to design a bone-like scaffold, for which the interconnected porous microstructure with a relatively large pore diameter could be applied for cell attachment and growth. Because a scaffold should also be a biomimetic structure, with biomimetic physical and mechanical properties, further study would include investigating the mechanical properties of scaffolds, which is just as important as the biodegradability of the material. 


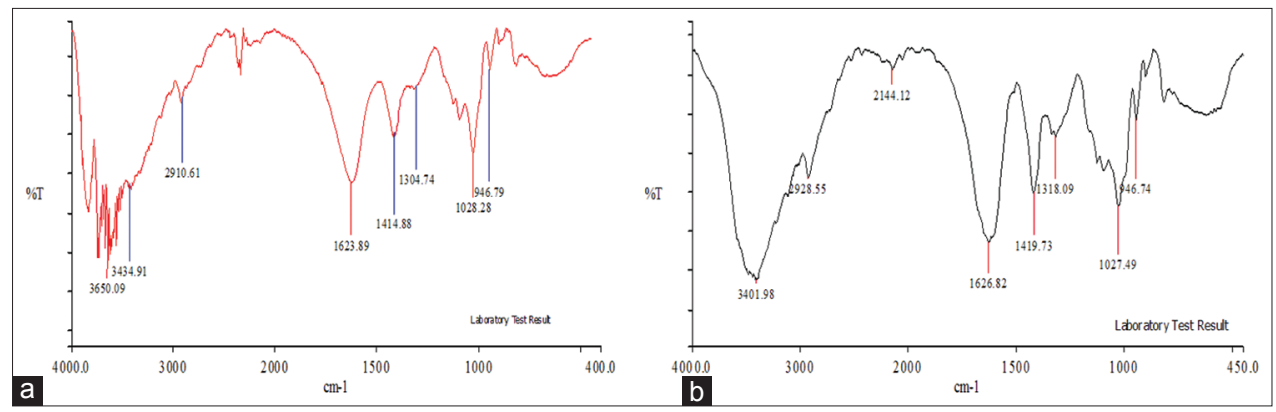

Fig. 3: Fourier transform infrared spectra of the (a) synthesized and (b) the commercially available alginate
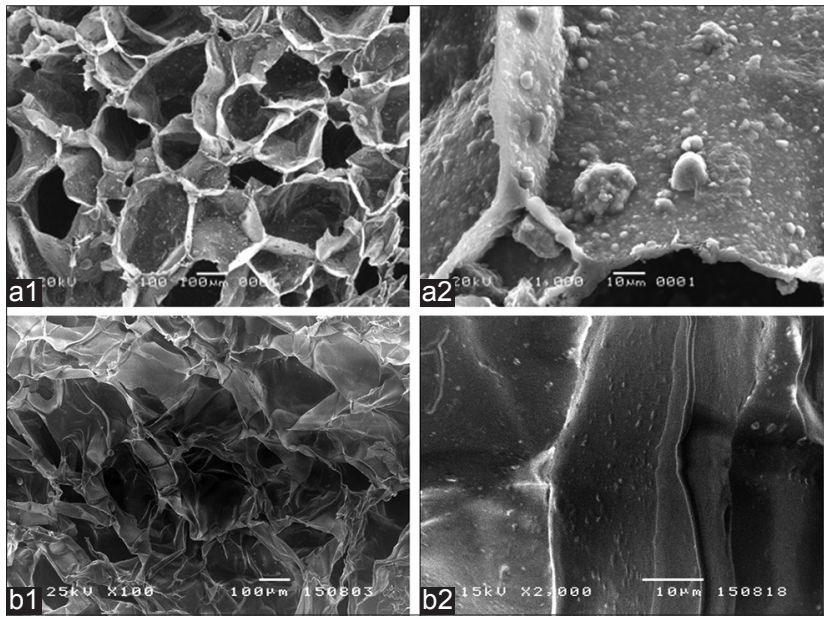

Fig. 4: Micrographs of the (a1, a2) experimental hydroxyapatite (HA)/alginate and (b1, b2) commercially available HA/alginate composite scaffolds

\section{CONCLUSION}

Mixtures of the synthesized HA and the high viscosity alginate solution has produced three-dimensional experimental HA/alginate scaffolds constructed from the HA/alginate composite structure. The scaffolds showed interconnected pores, with a diameter ranging from 150 to $300 \mu \mathrm{m}$.

\section{ACKNOWLEDGMENT}

The authors appreciate the financial support from the Ministry of Research, Technology and Higher Education of Indonesia. The publication of this manuscript is supported by Universitas Indonesia.

\section{REFERENCES}

1. Vacanti CA, Bonnassar LJ, Vacanti JP. Structural tissue engineering. In: Lanza RP, Langer R, Vacan JP, editors. Principles of Tissue Engineering. San Diego: Academic Press; 2000. p. 671-82.

2. Payne KF, Balasundaram I, Debc S, Silvio LD, Fan KF. Tissue engineering technology and its possible applications in oral and maxilla facial surgery. Br J Oral Maxillofac Surg 2014:52:7-15.

3. Neel EA, Chrzanowski W, Salih VM, Kim HW, Knowles JC. Tissue engineering in dentistry. J Dent 2014;42:915-28.

4. Pilipchukb SP, Plonkaa AB, Monjea A, Tauta AD, Lanisa A, Kanga B. Tissue engineering for bone regeneration and osseointegration in the oral cavity. Dent Mater 2015;31:317-38.

5. O'Brien FJ. Biomaterials and scaffolds for tissue engineering. Marer Today 2011;14:88-95.

6. Wang P, Zhao L, Liu J, Weir MD, Zhou X, Xu HH. Bone tissue engineering via nanostructured calcium phosphate biomaterials and stem cells. Bone Res 2014;2:14017.

7. Sanz AR, Carrión FS, Chaparro AP. Mesenchymal stem cells from the oral cavity and their potential value in tissue engineering. Periodontol 2000 2015;67:251-67.
8. Ghoraishizadeh S, Ghorishizadeh A, Ghoraishizadeh P, Daneshvar N, Boroojerdi MH. Application of nano-scaffolds in mesenchymal stem cell-based therapy. Adv Regen Med 2014;20:369-98.

9. Rai S, Kaur M, Kaur S. Applications of stem cells in interdisciplinary dentistry and beyond: An overview. Ann Med Health Sci Res 2013;3:245-54.

10. Currey JD. Bones: Structure and Mechanics. Princeton, NJ: Princeton University Press; 2002

11. Lett JA, Sundareswari M, Ravichandran K. Porous hydroxyapatite scaffolds for orthopedic and dental applications-the role of binders. Mater Today Proc 2016;3:1672-7.

12. Kumar A, Negi YS, Choudhary V, Bhardwaj NK. Microstructural and mechanical properties of porous biocomposite scaffolds based on polyvinyl alcohol, nano-hydroxyapatite and cellulose nanocrystals. Cellulose 2014;21:3409-26.

13. Cholas R, Padmanabhan SK, Gervaso F, Udayan G, Monaco G, Sannino A, et al. Scaffolds for bone regeneration made of hydroxyapatite microspheres in a collagen matrix. Mater Sci Eng C Mater Biol Appl 2016;63:499-505.

14. Islam S, Todo M. Effects of properties of collagen/hydroxyapatite composite scaffolds for bone tissue engineering. Mater Lett 2016;173:231-4

15. Ghorbani F, Nojehdehian H, Zamanian A. Physicochemical and mechanical properties of freeze cast hydroxyapatite-gelatin scaffolds with dexamethasone loaded PLGA microspheres for hard tissue engineering applications. Mater Sci Eng C Mater Biol Appl 2016;69:208-20

16. Rogina A, Rico P, Ferrer GG, Ivanković M, Ivanković H. Effect of in situ formed hydroxyapatite on microstructure of freeze-gelled chitosan-based bio-composite scaffolds. Eur Polym J 2015;68:278-87.

17. Shaji J, Shaikh M. Formulation, optimization, and characterization of biocompatible inhalable D-cycloserine-loaded alginate-chitosan nanoparticles for pulmonary drug delivery. Asian J Pharm Clin Res 2016;9:82-95.

18. Sailaja AK, Amareshwar P. Preparation of alginate nanoparticles by desolvation technique using acetone as desolvating agent. Asian J Pharm Clin Res 2012;5:132-4

19. Han J, Zhou Z, Yin R, Yang D, Nie J. Alginate-chitosan/hydroxyapatite polyelectrolyte complex porous scaffolds: Preparation and characterization. Int J Biol Macromol 2010;46:199-205.

20. Kim HL, Jung GY, Yoon JH, Han JS, Park YJ, Kim DG, et al. Preparation and characterization of nano-sized hydroxyapatite/alginate/ chitosan composite scaffolds for bone tissue engineering. Mater Sci Eng C Mater Biol Appl 2015;54:20-5.

21. Hu Y, Ma S, Yang Z, Zhou W, Du Z, Huang J, et al. Facile fabrication of poly(L-lactic acid) microsphere-incorporated calcium alginate/ hydroxyapatite porous scaffolds based on Pickering emulsion templates. Colloids Surf B Biointerfaces 2016;140:382-91

22. Nazarpak MH, Pourasgari F. Fabrication of tissue engineering scaffold from hydroxyapatite/alginate composite. Int $\mathrm{J}$ Biosci Biochem Bioinform 2014;4:142-5

23. Parthiban C, Parameswari K, Saranya C, Hemalatha A, Anantharaman P. Production of sodium alginate from selected seaweeds and their physiochemical and biochemical properties. Asian Pac J Trop Biomed 2012;1:1-4.

24. Chee SY, Wong PK, Wong CL. Extraction and characterization of alginate from brown seaweed (Fucales, Phaeophyciae) collected from Port Dickson, Peninsular Malaysia. J Appl Phycol 2011;23:191-6.

25. Rhein-Knudsen N, Ale MT, Ajalloueian F, Meyer AS. Characterization of alginates from Ghanaian brown seaweeds: Sargassum spp and 
Padina spp. Food Hydrocoll 2017;71:236-44.

26. Ramesh K, Krishnapriya M, Paul A, Nair SC. Preparation and evaluation of chitosan sodium alginate carbamazepine microspheres. Asian J Pharm Res 2017;10:271-6.

27. Sharma M, Choudhury P, Dev SK. Formulation and in-vitro-in-vivo evaluation of alginate-chitosan microspheres of glipizide by ionic gelation method. Asian J Pharm Res 2017;10:385-90.

28. Wouthuyzen S, Herandarudewi SM, Komatsu T. Stock assessment of brown seaweed (Phaeophyceae) along the bitung-bentena Coast, North Sulawesi province, Indonesia for alginate product using satellite remote sensing. Procedia Environ Sci 2016;33:553-61.

29. Mushollaeni W. The physicochemical characteristics of sodium alginate from Indonesian brown seaweeds. Afr J Food Sci 2011;5:349-52.

30. Perryman SE, Lapong I, Mustafa A, Sabang R, Rimmer MA.
Potential of metal contamination to affect the food safety of seaweed (Caulerpa spp.) cultured in coastal ponds in Sulawesi, Indonesia. Aquac Rep 2017;5:27-33.

31. Indrani DJ, Budianto E. A study of extraction and characterization of alginates obtained from brown macroalgae Sargassum duplicssatum and Sargassum crassifolium from Indonesia. Dent J 2013;46:65-70.

32. Chandrasekar A, Sagadevan S, Dakshnamoorthy A. Synthesis and characterization of nano-hydroxyapatite (n-HAP) using the wet chemical technique. Int J Phys Sci 2013;8:1639-45.

33. Bouyer E, Gitzhofer F, Boulos MI. Morphological study of hydroxyaatite nanocrystal suspension. J Mater Sci Mater Med 2000;11:523-31

34. Shi X, Wang Y, Wei K, Ren L, Lai C. Self-assembly of nanohydroxyapatite in mesoporous silica. J Mater Sci Mater Med 2008:19:2933-40 